\title{
La enseñanza de la Medicina Legal en Sevilla (1824-2006): nómina de catedráticos.
}

Teaching Forensic Medicine in Seville (Spain) (1824-2006): Roll of Professors.

JL. Carrillo ${ }^{1}$

\section{RESUMEN}

El presente artículo es una aportación al conocimiento de la genealogía de los catedráticos que enseñaron Medicina Legal (y Toxicología) en las distintas instituciones docentes de Sevilla desde 1824 hasta la actualidad.

Palabras clave: medicina legal, catedráticos, siglos XIX y XX Sevilla.

Cuad Med Forense 2005; 11(42):261-266

\section{ABSTRACT}

The present article is a new contribution to the knowledge of the genealogy of professors who have taught Forensic Medicine in the various schools existing in Seville from 1824 up until today.

Key words: forensic medicine, professors, nineteenth- and twentieth-century, Seville (Spain).

Correspondencia: Dr. Juan L. Carrillo. Departamento de Psiquiatría. Facultad de Medicina. Avda. Sánchez Pizjuán s/n 41009 Sevilla. E-mail: jlcarri@us.es.

1 Catedrático de Historia de la Medicina. Departamento de Psiquiatría. Universidad de Sevilla. 


\section{INTRODUCCIÓN:}

La dotación de cátedras universitarias es sin duda un firme indicador del proceso de emergencia de una especialidad médica y como tal se ha venido utilizando en los estudios históricos sobre los orígenes de la Medicina Legal en España. Sin embargo el subindicador "ocupación" en raras ocasiones se ha tenido en cuenta. Pues bien, sólo cuando se dispongan de genealogías sólidas -hasta ahora sólo disponíamos de las de Barcelona y Granada- se podrá valorar más adecuadamente el proceso de institucionalización y profesionalización de esta especialidad médica. El presente artículo pretende contribuir al conocimiento de estas genealogías, primero en la Universidad Literaria de Sevilla (|824-|845) y después en la Escuela Libre de Medicina fundada por Federico Rubio y Galí (1827-1902) en 1868 y en las sucesivas transformaciones que sufrió hasta integrarse definitivamente en 1917 en la Universidad Hispalense.

Desde 1803 era propietario de la cátedra de Método de la Universidad Literaria de Sevilla el Dr. Joaquín de Parias y Ramírez. En 1807 esta cátedra tenía unas rentas anuales de 270 reales, se dictaba en los cursos $3^{\circ}$ y $4^{\circ}$, su contenido correspondía a la parte $5^{a}$ de las Instituciones Médicas, es decir, a la Terapéutica y se enseñaba por Boerhaave. Sabemos que a comienzos de I 820 ya había extendido su contenido a las partes $3^{a}$ y $4^{a}$ de las Instituciones Médicas, es decir, contemplaba también el estudio de la Semiótica y de la Higiene. Boerhaave continuaba siendo el texto de referencia. Como en tantos otros aspectos la Real Orden de 14 de octubre de 1824 que implantó un "nuevo Plan General de Estudios en todas las Universidades del reino", diseñado por el P. Manuel Martínez y conocido comúnmente por "Plan Calomarde", modificó sustancialmente el contenido de la cátedra de Método, que a partir de ahora se llamaría Instituciones Médicas de $3^{\circ}$ curso, en el sentido de mantener la enseñanza tradicional de la Terapéutica, suprimir la enseñanza de la Semiótica y la Higiene en este curso y como gran novedad introducir la de la Medicina Legal. Terapéutica, Materia Médica y Medicina Legal serán sus contenidos.

Este maridaje entre la Medicina Legal y la Terapéutica no se rompió hasta I 843 (Plan Mata) fecha en que alcanzó su independencia académica, pero aquel Plan determinó el cierre de la Facultad de Medicina en Sevilla, permaneciendo Cádiz como única Facultad de Medicina de la Universidad Literaria de Sevilla. Sin embargo en Sevilla se creó un Colegio de "Prácticos en el Arte de Curar" en el que no se emancipó la Medicina Legal enseñándose por el mismo profesor que impartía la Patología General y la Clínica Médica. Las características generales de los catedráticos que enseñaron la Medicina Legal en Sevilla entre 1824 y 1845 pueden resumirse en las siguientes: carecer de una formación especializada, limitarse a la lectura en la cátedra del Curso de medicina legal, teórica y práctica (Madrid, 1819; $2^{\mathrm{a}}$ ed. 1827) de Jean Jacques Belloc ( 1730 - 1807) y obtener la cátedra en oposiciones locales o ser nombrados por el claustro universitario o por el gobierno.

La recuperación de los estudios médicos para la ciudad de Sevilla no se produjo hasta I 868 en que por Decreto de la Junta Revolucionaria y a propuesta de Federico Rubio se creó la Escuela Libre de Medicina y Cirugía. Esta institución docente sufrió una serie de cambios hasta 
que en 1917 se integró definitivamente en la Universidad de Sevilla. Antes se vio afectada por dos procesos de transformación: el primero en 1875 en que pasó a ser la Escuela Provincial de Medicina de Sevilla y el segundo en 1902 al convertirse en Facultad Provincial de Medicina y Cirugía. Esta vinculación institucional a la Diputación Provincial de Sevilla tuvo un efecto sobre el proceso de reclutamiento del profesorado. Entre 1868 y 1902 los catedráticos de Medicina Legal y Toxicología alcanzaron tal condición a través de un nombramiento y fueron extraídos entre médicos que ejercían su profesión en Sevilla. Ninguno puede ser considerado como un auténtico especialista dándose algunas circunstancias dignas de mención: la renuncia en 1869 de Carlos Morón Delgado -la identificación de este profesor ha presentado dificultades ya totalmente superadas- determinó la separación entre 1870 y 1874 de la Medicina Legal y la Toxicología encargándose sucesivamente de esta última al ingeniero químico Pascual Vincent González de la Hoyuela (n. 1842) primero y al médico José Barroso Rodríguez (n. 1824) después; por otra parte Ramón de la Sota y Lastra renunció a esta cátedra en 1874 porque "no era de su agrado, que no tenía estudios hechos acerca de esa materia y que se atrevía a decir que le era repulsiva", encargándose después su enseñanza a Antonio Sánchez Rivera, catedrático de Anatomía Patológica, el más cercano de todos los profesores de esta época a la patología forense. Le sucedió Narciso Vázquez García que en 1902 sería integrado en el cuerpo de catedráticos, pero con la limitación de no poder trasladarse a otra universidad.

Tras la muerte de este último en 1907 la cátedra de Medicina Legal y Toxicología se vio sometida a los mecanismos habituales para la ocupación de cátedras universitarias (oposición, traslado o permuta) y ya no volvería a ser ocupada por un sevillano tanto si era de nacimiento como surgido, en tanto que médico, del entorno sevillano; pero como contrapartida los catedráticos tuvieron ya un alto grado de especialización. Entre 1907 y 1910 se encargó de la enseñanza un profesor auxiliar que, como todos, era un auténtico "comodín docente", es este caso se trató de Guillermo Vilches Romero (I875-c. 1952). Una década especialmente interesante es la de los años 10 donde pasaron por Sevilla dos grandísimos medico-legistas Juan Bautista Peset Aleixandre y Antonio Lecha Marzo. Como había ocurrido antes la cátedra estuvo vacante entre 1919 y 1923 y en este periodo se encargó de la docencia otro profesor auxiliar como era Manuel Moreno Parra (1862-1927). La novedad más importante tras la llegada de Francisco Javier Aguilar Castelló en 1923 ha consistido en el hecho de que todos los catedráticos han terminado su vida académica en Sevilla y que procedían de otra Facultad, llegando a nuestra ciudad en virtud de concursos de traslado o de acceso. En tal sentido la cátedra sevillana se convirtió en una institución apetecible y quienes la han ocupado lo han hecho con vocación de permanencia. Si en sólo trece años (1910-1923) fue ocupada por cuatro catedráticos, este mismo número son los que la han regentado en los ochenta y tres años que van desde 1923 hasta el momento actual. 


\section{NÓMINA DE CATEDRÁTICOS:}

PARIAS Y RAMÍREZ, Joaquín de [m. Sevilla, I826]

Catedrático propietario de Método por Real Orden de 16 de enero de 1803. Enseñó Medicina Legal durante los cursos | 824- | 825 y | 825- | 826 hasta su fallecimiento.

RODRÍGUEZ DE VERA, Gabriel [Sevilla c. I766-Sevilla I833]

Catedrático sustituto de Instituciones Médicas de $3^{\circ}$ año (Terapéutica, Materia Médica y Medicina Legal) nombrado por el Claustro de la Universidad de Sevilla el 18 de octubre de 1826 hasta su fallecimiento.

SÁNCHEZ-RECIENTE DÍAZ, Joaquín [Cantillana (Sevilla) c. | 80 | - d. I844]

Catedrático de Instituciones Médicas de $3^{\circ}$ año (Terapéutica, Materia Médica y Medicina Legal) nombrado en virtud de oposición por Real Cédula de 2 de septiembre de 1834 hasta que por Real Orden de 23 de septiembre de 1840 (ejecutada en Claustro de la Universidad de Sevilla el 26 de septiembre de 1840) fue desposeído de la cátedra.

VIDA PÉREZ, Fernando [Écija (Sevilla) I799-d. I873]

Catedrático sustituto de Instituciones Médicas de $3^{\text {a }}$ año (Terapéutica, Materia Médica y Medicina Legal) nombrado por el Claustro de la Universidad Literaria de Sevilla el día 26 de septiembre de I 840 (catedrático interino por acuerdo votado en Claustro el 3 de noviembre de 1840) hasta el cierre de la Facultad de Medicina de la Universidad de Sevilla por Real Decreto de 10 de octubre de 1843.

ADAME DE VARGAS JIMÉNEZ, Serafín [Sevilla c. I774-Sevilla 20.X. I 852]

Catedrático de Patología General, Medicina Legal y Clínica Médica nombrado por el Gobierno el 6 de noviembre de 1843 para el Colegio de "Prácticos en el Arte de Curar" hasta que por Real Decreto de 17 de septiembre de 1845 se suprimió en Sevilla el mencionado Colegio.

MORÓN DELGADO, Carlos [Alcalá del Río (Sevilla) I0.XI. I 82 I-Sevilla 29.VII. I88 I]

Catedrático de Medicina Legal y Toxicología nombrado a propuesta de Federico Rubio y Galí en el reparto de cátedras efectuado el 28 de octubre de 1868 , renunciando el 2 I de diciembre de 1869 .

SÁNCHEZ RIVERA, Antonio [Jerez de la Frontera (Cádiz) 30.IX. I 823-Sevilla II.VI. I 878 ]

Catedrático sustituto de Medicina Legal nombrado por el Claustro de la Escuela Libre de Medicina y Cirugía el 26 de enero de 1870 hasta el 23 de octubre de 1874. Nuevamente fue nombrado por Real Orden de 7 de octubre de 1875 como catedrático de Medicina Legal y Toxicología hasta su fallecimiento.

SOTA Y LASTRA, Ramón de la [Santander 8.XII. | 832- Sevilla 23.VII. 1913]

Nombrado Catedrático de Medicina Legal y Toxicología por la Dirección General de Instrucción Pública a propuesta de la Diputación Provincial de Sevilla ejecutado en Claustro de la Escuela Libre el 23 de octubre de 1874. No aceptó este nombramiento pero se comprometió a impartir la docencia hasta que se encontrara un sustituto.

VÁZQUEZ GARCíA, Narciso [Cortegana (Huelva) I I .IX. I 850-Sevilla 2.V. I907]

Catedrático de Medicina Legal y Toxicología en la Escuela Provincial de Medicina y Cirugía de Sevilla nombrado por Real Orden de 9 de julio de 1878. Al convertirse en Facultad Provincial de Medicina por Real Decreto de 24 de enero de 1902 se le confirmó el 31 de enero de 1902 como Catedrático de Medicina Legal y Toxicología continuando hasta su fallecimiento. 
PESET ALEIXANDRE, Juan Bautista [Godella (Valencia) 2.VII. I 886-Paterna (Valencia) 24.V. I 94I] Catedrático de Medicina Legal y Toxicología de la Facultad Provincial de Medicina y Cirugía de Sevilla nombrado por Real Orden de 31 de mayo de 1910 (toma de posesión el 3 de junio de 1910) en virtud de oposición hasta que por Real Orden de 8 de agosto de 1916 fue trasladado por permuta a la Universidad de Valencia.

ORTS Y ORTS, Francisco [Polop (Alicante) 5.X. I 844-d. 19|7]

Catedrático de Medicina Legal y Toxicología de la Facultad Provincial de Medicina y Cirugía de Sevilla nombrado por Real Orden de 8 de agosto de 1916 hasta su jubilación por Real Orden de 21 de febrero de 1917. Procedía por permuta de la Universidad de Valencia.

LECHA MARZO, Antonio [Porac (isla de Luzón, Filipinas) 7.II. I 888-Sevilla 19.V. I919]

Catedrático de Medicina Legal y Toxicología de la Facultad de Medicina de la Universidad de Sevilla nombrado por Real Orden de 9 de mayo de 1917 (toma de posesión el 15 de junio de 1917) hasta su fallecimiento. Procedía de la Universidad de Granada.

PASCUAL Y RIOS, Salvador [La Unión (Murcia) 7.III. I 888-San Sebastián V. I 939]

Catedrático de Medicina Legal y Toxicología de la Facultad de Medicina de la Universidad de Sevilla nombrado por Real Orden de 20 de febrero de 1923 en virtud de oposición. Por Real Orden de 26 de febrero de 1923 se le concedió la excedencia.

AGUILAR CASTELLó, Francisco Javier [Valencia 7.VII. I 897-Sevilla 5.XI. I 950]

Catedrático de Medicina Legal y Toxicología de la Facultad de Medicina de la Universidad de Sevilla nombrado por Real Orden de 5 de mayo de 1923 (toma de posesión el I de junio de 1923) hasta su fallecimiento. Procedía de la Universidad de Santiago de Compostela.

GUIJA MORALES, Eduardo [Casatejada (Cáceres) 9.III. I 904-Sevilla 27.X. I 966]

Catedrático de Medicina Legal y Toxicología de la Facultad de Medicina de la Universidad de Sevilla nombrado por Orden Ministerial de 27 de junio de 195I hasta su fallecimiento el 27 de octubre de 1966. Procedía de la Facultad de Medicina de Cádiz de la Universidad de Sevilla.

DOMÍNGUEZ MARTíNEZ, José María [Granada 28.X. 1908-Sevilla I3.III.2000]

Catedrático de Medicina Legal y Toxicología de la Facultad de Medicina de la Universidad de Sevilla nombrado por Orden Ministerial de II de enero de 1967 (toma de posesión el 18 de febrero de 1967) hasta su jubilación el 28 de octubre de 1978. Procedía de la Facultad de Medicina de Cádiz de la Universidad de Sevilla.

FRONTELA CARRERAS, Luís [Melilla 3 I.I. I94 I]

Catedrático de Medicina Legal y Toxicología (actual área de conocimiento Medicina Legal y Forense) de la Universidad de Sevilla nombrado por Orden Ministerial de 10 de junio de 1980 (toma de posesión el 13 de junio de 1980) en virtud de concurso de acceso entre profesores Agregados. Continúa en activo. 


\section{BIBLIOGRAFÍA:}

I. Álvarez Sierra J: Diccionario de autoridades médicas. Editora Nacional. Madrid, 1963. p. 393.

2. Carrillo JL: Medicina y enseñanza de la medicina en Sevilla (1868-1883): continuidad y cambio. Dynamis 1990; 10: $163-192$

3. Carrillo JL: Los orígenes de la Medicina Legal como especialidad en España. Cuad Med For 1996; 6: 13-17.

4. Carrillo JL: 1901-1902. Del desánimo a la euforia. Un episodio de la historia de la enseñanza de la medicina en Sevilla. Edición facsímil de la "Memoria estadística del curso académico 190I a 1902". Universidad de Sevilla. Sevilla, 1998.

5. Carrillo JL: La enseñanza clínica en la Universidad Literaria de Sevilla (1802-1845). Cronos 2000; 3: 297-312.

6. Carrillo JL: La enseñanza de la medicina en Sevilla. En: Danon J. La enseñanza de la medicina en la Universidad española. Fundación Uriach 1838. Barcelona, 200I. pp. 79-97.

7. Carrillo JL: De la consolidación a la cesantía: evolución del profesorado de medicina en la Universidad Literaria de Sevilla (18331845). Asclepio 2002; 54: 251-268.

8. Carrillo JL: Prácticas fraudulentas en la cultura académica: a propósito de un conflicto en la Universidad Literaria de Sevilla (1835). Cronos 2004; 7: 155-164.

9. Carrillo JL, Castellanos J: Antonio Lecha-Marzo (I888-1919). Bio-bibliografía. [Premio Fundación Frontela de Medicina Legal y Ciencias afines]. Málaga, 1983.

10. Carrillo JL, Olagüe G: La enseñanza de la Anatomía en las Universidades andaluzas. Edición facsímil del "Resumen de Anatomía" (Sevilla, 1828) de Joaquín Sánchez Reciente. Universidad de Sevilla. Sevilla, 200I.
II. Carrillo LL, Trigueros Gordillo G: La Universidad de Sevilla en el Sexenio Democrático (1868-1874). En: Serrera RM, Sánchez Mantero R. La Universidad de Sevilla 1505-2005. Universidad de Sevilla/Fundación El Monte, Sevilla, 2005. pp. 299-325.

12. Corbella J: Antecedentes históricos de la Medicina Legal en España. Promociones y Publicaciones Universitarias S. A., Barcelona, 1995.

13. Corbella J: Història de la Facultat de Medicina de Barcelona 1843-1985. Fundació Uriach 1838, Barcelona, 1996. p. 363.

14. Laín Entralgo P: Juan Peset Aleixandre 1886-194I. En: Estudios dedicados a Juan Peset Aleixandre. Universidad de Valencia, Valencia, I982. vol. I, pp. XXI-XXVII.

15. Martínez Montsó F: La enseñanza de la Medicina Legal en Valencia: la obra de Francisco Orts y Orts (1875-1916). En: Martínez Pérez J et al., La medicina ante el nuevo milenio: una perspectiva histórica. Universidad de Castilla-La Mancha, Cuenca, 2004. pp. 135-148.

16. Martínez Pérez J: Lecha-Marzo, Antonio (1888-1919). En: Ortiz García C, Sánchez Gómez LA. Diccionario histórico de la antropología española. CSIC, Madrid, 1995. pp. 434-437.

17. Navarro Hinojosa R: La Universidad de Sevilla de 1824 a 1845: Organización y Currículum. Universidad de Sevilla, Sevilla, 1991. pp. 453-455.

18. Olagüe de Ros G: Sobre sólida roca fundada: Ciento veinte años de labor docente, asistencial e investigadora en la Facultad de Medicina de Granada (1857-1976). Editorial Universidad de Granada, Granada, 2001. pp. 342-343.

19. Pérez Calero AM: Francisco Javier Aguilar Castelló. En: Médicos ilustres de Sevilla (1929-1939). Imprenta Flores, Sevilla, 1989. pp. II-I4. 